Original article

\title{
Prevalence and risk factors of anemia among children 6-59 months in India: A multilevel analysis
}

\author{
Mili Dutta ${ }^{\mathrm{a}}$, Mahadev Bhise ${ }^{\mathrm{a}}$, Lokender Prashad ${ }^{\mathrm{b}}$, Himanshu Chaurasia ${ }^{\mathrm{c}, *}$, Paramita Debnath $^{\mathrm{a}}$ \\ ${ }^{a}$ International Institute for Population Sciences (IIPS), India \\ ${ }^{\mathrm{b}}$ Tata Institute of Social Sciences (TISS), India \\ ${ }^{\mathrm{c}}$ National Institute for Research in Reproductive Health (NIRRH), India
}

\section{A R T I C L E I N F O}

\section{Keywords:}

Anemia

Individual-level effects

Community-level effects

Multilevel modelling

India

\begin{abstract}
A B S T R A C T
Background: Early detection of anemia and subsequent measures to prevent anemia can help children grow healthily. There is considerable attention given to the impact of individual-level factors on Anaemia, but less is known about how community characteristics affect Anaemia among children. The present study was focused at estimating the prevalence and associated risk factors at individual and community level in India among children aged 6-59 months in India.

Methods: Descriptive statistics and the chi-square test were applied using fourth round of National Family Health Survey dataset. Later, to explore the association of child anemia and some potential risk factors regarding hierarchy (individual and community level) of data, a multilevel logistic regression model was conducted using STATA-SE 14 software.

Results: The results indicate that some aspects of the community influence the anemia risks of children. For instance, a $1 \%$ increase in the proportion of mother education in the community decreased the likelihood of anemia by $9 \%$ among children. Northeast region was the only region at lesser risk of anemia. Higher community level ethnic and religious homogeneity is associated with decreased odds of anemia among children. Children aged 12-35 months, girl child, children having diarrhoea, mothers of age group 15-24, high parity and low exposure to mass-media were the high risk individual factors of anemia among children.

Conclusions: Overall, the present study indicated the requirement to include community-level factors beyond the individual level factors by policymakers to eradicate the burden of anemia in the country and the high prevalence states.
\end{abstract}

\section{Background}

Childhood anemia is a major public health concern affecting both developed and developing countries. Worldwide 1.6 billion people suffer from anemia of which two-thirds are under preschool children., It is an important indicator of both nutrition and health that affects the cognitive functioning, school performance, motor performance, and physical and behavioural growth of the children. ${ }^{3,4}$ It is also a cause of morbidity and mortality among children in developing countries. ${ }^{5}$ According to the World Health Organization (WHO) criteria, the condition of anemia is said to be a severe public health problem if its prevalence is $40 \%$ or more. Also, according to the WHO Classification of countries by degree of public health significance of anemia, India comes under the severe category for both children and pregnant women. ${ }^{6}$ The findings of the NFHS third-round survey shows nearly $80 \%$ of Indian children aged
12-23 months were anemic. ${ }^{7,8}$ Moreover, literature has cited the high burden of anemia in low and middle-income countries. ${ }^{9,10}$

The primary cause of all types of anemia in the world is due to iron deficiency, and young children are more vulnerable to this disease because of their rapid growth and need of high iron. According to World Bank reports, children of less than two years are at very high risk for anemia as their requirements for iron is higher than any other group. ${ }^{11}$ A diet which is low in iron is most often the reason behind IDA in infants, toddlers, and teens. The Children who do not eat enough or who eat food items that are poor sources of iron are at risk of developing the condition. Poverty is also a major contributing factor to Iron Deficiency Anemia because families living at or below the poverty line may not be getting enough iron-rich foods. Anemia can make children very ill and can put them at risk for learning difficulties and behavioural problems. ${ }^{12}$ It is a problem that contributes to low birth weight,

\footnotetext{
* Corresponding author.

E-mail address: himanshu.icmr369@gmail.com (H. Chaurasia).
} 
lowered resistance to infection, and decreased work capacity in future. However, in developing countries, iron deficiency may not always be the only or primary cause of anemia ${ }^{13}$; in fact, can also result from other nutritional deficiencies, such as folate and vitamin B12, malaria, other infectious and parasitic diseases. ${ }^{14,15}$ Also, many studies have found a positive association between vitamin A deficiency and anemia. ${ }^{16,17}$ The prevalence of anemia in the developing countries is very high and is multi-factorial that often coincide. ${ }^{18,19}$ The factors involve socioeconomic, nutritional, biological, environmental, and cultural characteristics. $^{20}$

The literature, most often, also cite some specific risk factors of anemia as low family income and low maternal level of education, lack of access to health care services, inadequate sanitary conditions and a diet with insufficient quantities of iron. ${ }^{21,22}$ There is substantial evidence that children in the age group of 6-59, who are living in the lowincome household are at higher risk of anemia compared to those with higher income. ${ }^{23-25}$ Inadequate access to food and poor sanitation are often correlated with low income and to some extent, explain the higher risk of anemia among these children. ${ }^{22,26-28}$ Parent's level of education constitutes a well-documented determinant of anemia in children because educated parents are more likely to have well-paid employment and also more likely to adopt healthier dietary behaviour. ${ }^{29}$ The mother's level of education, in its turn, influences the practices related to the child's health care. ${ }^{30}$ The age of the child is another risk factor for anemia, and many studies have found to vary the causes of anemia with age. ${ }^{31,32}$ In a study, have demonstrated that children between 6 and 24 months have a significantly higher prevalence of anemia (two times) when compared to children between 24 and 59 months. ${ }^{33}$ Previous studies have demonstrated that the incidence of anaemia can vary between males and females. ${ }^{25,34}$ However, most authors have shown that there is no difference in the prevalence of anemia or haemoglobin concentration regarding gender. ${ }^{25,35,36}$ Community level factors play an essential role in the risk of anemia. Previous studies have documented the higher risk of anemia in children of rural. ${ }^{23,25,37,38}$ The disease was found to be higher in lower Caste population in some parts of India. ${ }^{39,40}$

Anemia has severe consequences on growth, development, and survival of a child; and the factors which influence the occurrence of anemia in a population are fundamental to the implementation of control measures. The findings of the study on the prevalence of anemia, and also its associated factors will help to set up preventive programs, updating of the treatment protocols, follow up and care of anemic children, formulation of policies, and also to create public awareness about child anemia in India.

\section{Methods}

The data on anemia status of children along with some significant biological, socioeconomic, demographic, ethnic and dietary pieces of evidence were gathered from the database of NFHS-IV (National Family Health survey, 2005-06, Govt. of India). ${ }^{41}$ It is a nationally representative sample survey, provides information on population, nutrition and health. It covers each state and union territory of India. The study was conducted under the guidance of Ministry of Health and Family Welfare (MoHFW), Government of India and the International Institute for Population Sciences (IIPS) is a nodal agency for conducting the survey. The survey follows a stratified two-stage sampling process. The primary sampling unit (PSU) was the villages for rural areas, and Census Enumeration Blocks (CEBs) in urban areas and the household was the second stage sampling unit (SSU) for both rural and urban areas. The PSU was selected using the probability proportional to size (PPS) sampling and households were selected using the systematic sampling procedure. Four type of survey questionnaire (household, women, men and biomarker) were canvassed in the survey.

\section{Measurement of variables}

Outcome Variable: The anemia level among children was measured by the haemoglobin concentration level with the help of a portable HemoCue $\mathrm{Hb} 201+$ analyser in the survey. The HemoCue has been found to give very accurate results, comparable to estimates from more sophisticated laboratory instruments. ${ }^{42,43}$ The anemia level among children was categorised as 1 if haemoglobin level less than $11.0 \mathrm{~g} / \mathrm{dl}$ (anemic) and 0 otherwise.

\subsection{Explanatory variables}

Depending of the severity of diarrhoea, it could lead to mild, moderate, or severe anemia. ${ }^{31}$ Diarrheal illness is associated with loss of iron and decreased absorption of nutrients needed to maintain normal haemoglobin status. ${ }^{32}$ It is also likely that, as demonstrated for other nutrient deficiencies, diarrhoea shares common cause with anemia. ${ }^{33,34}$ Bednet use is well documented as an effective anemia prevention strategy. ${ }^{14,35-42}$ A recent study in Mali estimated that $30 \%$ of anemia is due to malaria. ${ }^{43}$ An exhaustive review of the impact of malaria control on the risk of anemia among children ${ }^{14}$ estimates the protective efficacy of bednet usage on severe anemia to be $60 \%$ (hemoglobin $<8 \mathrm{~g} / \mathrm{dL}$ ).

The study variables for the present study was selected based on the existing literature on anemia. The explanatory variables taken in the study are child age in months (6-11, 12-35, 36+), sex (boy, girl), type of birth (single, multiple), size of the child (very small, small, average/ large). The presence of diarrhoea (no, yes) and fever (no, yes) within last two weeks from the date of interview was considered. The presence of diarrhoea and fever is associated with the loss of iron and decreased absorption of nutrients which can affect the anemia level. ${ }^{44}$ The other variables considered in the study are bed net (no, yes), full immunization (yes, no), age of mother (15-24, 25-34, 35-49), parity (first parity, 2-3 parity, 4 and above), currently working (no, yes), wealth index (richest, richer, middle, poorer, poorest), mass media (full exposure, partial exposure, no exposure), drinking water (unimproved, improved), latrine facility type (improved, unimproved), region (south, west, north east, east, central, north), place of residence (urban, rural), community education (low, high), Ethnic Fractionalization Index (totally homogenous, not homogenous), Religion Fractionalization Index (totally homogenous, not homogenous). The use of bed net is associated with incidence of malaria and bed net use is documented as an effective anemia prevention strategy. ${ }^{45,46}$

Community education variable was indicating the proportion of women aged 15-49 with secondary or higher education in the community is high or low. Ethnic Fractionalization Index and religion fractionalization index were used to show the ethnic and religious diversity in the community. The index was calculated as EFL $=1-\Sigma i$ (proportion of ethno-linguistic group/religious group $i$ in the population) ${ }^{2}$. The totally homogenous category shows there was no diversity and not homogenous category shows complete diversity. ${ }^{47}$ The ethnic and religious diversity are found to be associated with a larger talent pool and this could improve the quality of health workers in a community, which, a priori, promotes positive health or health outcomes. ${ }^{48}$

\subsection{Statistical analysis}

In the present study, the prevalence of anemia by different background characteristics was measured and presented in the form of a percentage. The Chi-square test at $5 \%$ level of significance, performed for measuring the association between different predictor variables and anemia. The multilevel logistic regression analysis was applied for determining the risk factors of anemia among children in India. 


\subsection{Multilevel logistic regression model}

The multilevel logistic regression model was used to analyse the determinants of anemia at three levels (fixed part model) - individual, community (PSU), and district. The random intercept model was used to measure the random effect or the clustering of participants at the community and district levels. Three models have been constructed for the analysis. The first model was an empty model that comprised of no exposure variables, and it focused on decomposing the total variance into the community (i.e. PSU) and the district components, which is useful to measure the extent of cluster variation in anemia. The second model adjusted for individual or child level variables, the third model adjusted for community-level variables while the fourth model was a full model and adjusted for both individual and community level variables simultaneously. Odds ratio, p-value, standard error (SE) and 95\% confidence interval have been shown in the table of fixed effect model.

The advantage of multilevel logistic regression (i.e. MLR) analysis is that it allowed us to partition the variations in the outcome variable, i.e. less than $7 \mathrm{~g} / \mathrm{dl}$ - severe anemia; 7.0-9.9 g/dl - moderate anemia; $10.0-10.9 \mathrm{~g} / \mathrm{dl}$ - mild anemia ${ }^{45}$ estimated at the individual level, and the variation is further attributable to the differences among individuals, communities and district level. Multicollinearity was examined using variance inflation factor (VIF) prior to multivariate analysis,.

The multilevel logistic model can be expressed as follows:

$\operatorname{logit}\left(p_{i j k}\right)=\log \left(\frac{p_{i j k}}{1-p_{i j k}}\right)=\alpha+\beta^{\prime} x_{i j k}+u_{j k}+v_{k}$

where, $\log \left(\frac{p_{i j k}}{1-p_{i j k}}\right)$ is the logit function, in which $p_{i j k}$ is the probability of children, ' $\mathrm{i}$ ' is the community ' $\mathrm{j}$ ' is the district, ' $\mathrm{k}$ ' being anemic. The ' $\alpha$ ' is the constant, and $\mu_{j k}$ and $v_{k}$ are the area level residual explained at the community and the district level.

The variance partition coefficient (i.e. VPC), which is useful to measure both cluster and individual level variance, is attributable to the community and the district level.

The VPC is calculated using the following formula:

$V P C_{c}=\frac{\sigma_{c}^{2}+\sigma_{d}^{2}}{\sigma_{c}^{2}+\sigma_{d}^{2}+\frac{\pi^{2}}{3}}$

$V P C_{d}=\frac{\sigma_{d}^{2}}{\sigma_{c}^{2}+\sigma_{d}^{2}+\frac{\pi^{2}}{3}}$

where, $\sigma_{c}^{2}$ is the community level variance and $\sigma_{d}^{2}$ shows district-level variance. The variance for the standard logistic distribution is $\frac{\pi^{2}}{3} \approx 3.29$.

Similarly, Median Odds Ratio (MOR) is useful to measure cluster level variance. It depends upon area level variance. The details are explained elsewhere. ${ }^{46}$

The MOR can be expressed as:

$M O R=\exp \left[\sqrt{\left(2 * V_{A}\right)} * 0.6745\right]$

$\approx \exp \left(0.95 * \sqrt{V_{A}}\right)$

where $\mathrm{V}_{\mathrm{A}}$ is area level variance, and 0.6745 is the 75th centile of the cumulative distribution function of the normal distribution with mean 0 and variance 1 .

All the statistical estimations and analyses are carried out with the help of the following software STATA 13 and MLwiN 2.28 software. However, ArcGIS 10 was used for creating the maps.

\section{Results and findings}

The Sample Distribution for respondent by their background
Table 1

Percentage Distribution of sample.

\begin{tabular}{|c|c|c|}
\hline Background Variables & $\%$ & $\mathrm{~N}$ \\
\hline \multicolumn{3}{|l|}{ Child Age (in months) } \\
\hline $6-11$ & 11.3 & 26657 \\
\hline $12-35$ & 43.7 & 103054 \\
\hline $36+$ & 45.0 & 106162 \\
\hline \multicolumn{3}{|l|}{ Sex of child } \\
\hline Boy & 52.1 & 122810 \\
\hline Girl & 47.9 & 113063 \\
\hline \multicolumn{3}{|l|}{ Type of Birth } \\
\hline Single & 98.4 & 231982 \\
\hline Multiple & 1.7 & 3891 \\
\hline \multicolumn{3}{|l|}{ Size of Child } \\
\hline Very small & 3.1 & 7197 \\
\hline Small & 9.2 & 21052 \\
\hline Average and above & 87.7 & 201703 \\
\hline \multicolumn{3}{|l|}{ Diarrhoea } \\
\hline No & 91.1 & 204854 \\
\hline Yes & 8.9 & 20047 \\
\hline \multicolumn{3}{|l|}{ Fever } \\
\hline No & 86.9 & 195496 \\
\hline Yes & 13.1 & 29405 \\
\hline \multicolumn{3}{|l|}{ Bed Net } \\
\hline No & 57.6 & 135743 \\
\hline Yes & 42.5 & 100130 \\
\hline \multicolumn{3}{|l|}{ Full Immunization } \\
\hline Yes & 86.1 & 120806 \\
\hline No & 13.9 & 19469 \\
\hline \multicolumn{3}{|l|}{ Age of Mother } \\
\hline $15-24$ & 31.0 & 73040 \\
\hline $25-34$ & 58.4 & 137833 \\
\hline $35-49$ & 10.6 & 25000 \\
\hline \multicolumn{3}{|l|}{ Parity } \\
\hline First parity & 37.0 & 87278 \\
\hline 2-3 Parity & 46.7 & 110084 \\
\hline $4+$ above & 16.3 & 38511 \\
\hline \multicolumn{3}{|l|}{ Currently Working } \\
\hline No & 82.0 & 33745 \\
\hline Yes & 18.0 & 7398 \\
\hline Wealth Index & & \\
\hline Richest & 13.4 & 31542 \\
\hline Richer & 16.6 & 39142 \\
\hline Middle & 20.0 & 47047 \\
\hline Poorer & 23.6 & 55631 \\
\hline Poorest & 26.5 & 62511 \\
\hline Mass Media & & \\
\hline Full Exposure & 7.0 & 16513 \\
\hline Partial Exposure & 64.9 & 153140 \\
\hline No Exposure & 28.1 & 66220 \\
\hline Drinking Water & & \\
\hline Improved & 83.7 & 197322 \\
\hline Unimproved & 16.3 & 38551 \\
\hline Latrine facility Type & & \\
\hline Improved & 48.4 & 114140 \\
\hline Unimproved & 51.6 & 121733 \\
\hline Region & & \\
\hline South & 10.0 & 23544 \\
\hline West & 7.1 & 16681 \\
\hline North East & 14.4 & 33847 \\
\hline East & 20.9 & 49290 \\
\hline Central & 29.0 & 68288 \\
\hline North & 18.8 & 44223 \\
\hline Place of Residence & & \\
\hline Urban & 23.8 & 56077 \\
\hline Rural & 76.2 & 179796 \\
\hline Community Educatio & & \\
\hline Low & 43.9 & 103549 \\
\hline High & 56.1 & 132324 \\
\hline Ethnic Fractionalizat & & \\
\hline Totally Homogeneous & 24.6 & 58050 \\
\hline Not Homogeneous & 75.4 & 177823 \\
\hline Religion Fractionaliz & & \\
\hline Totally Homogeneous & 66.5 & 156853 \\
\hline Not Homogeneous & 33.5 & 79020 \\
\hline Total & 100.0 & 235873 \\
\hline
\end{tabular}


characteristics is shown in Table 1 . The sample entails a higher proportion of children in the age group of $12-35$ and $36+$ months. The percentage of boy children is higher than the girl children. The table shows most of the births are single births. A higher percentage of children born average to large size in the sample. Nearly ninety percentages of children did not have diarrhoea and fever within the last two weeks from the date of the interview. A higher percentage (57.6\%) of the population use bed net. Full immunization is more prevalent in the study population. The women are mostly in the age group of 25-34 age group. Children mostly belong to second to third parity. A higher percentage of women are non-working. There is not much variation in the wealth index distribution within the sample. Mostly women have partial exposure to the mass media. A higher percentages use improved drinking water, however, use of unimproved latrine facility is higher in the sample. Central region consists of the higher percentage of the sample, although the lowest percentage of the sample is from the west region. More than seventy-five percentages of the sample are from the rural area. Community education is high in the sample. Also, it is evident, that the ethnic diversity is more prevalent, although religious diversity is not much prevalent in the sample.

Map 1 shows the state wise prevalence of anemia among children of 6-59 months. The national prevalence of anemia is found to be $58.7 \%$. The map shows union territories (UTs) having the highest prevalence of anemia among children in India. Among the UT's Dadra \& Nagar Haveli has the highest prevalence (84.4) followed by Daman \& Diu (74.4) and Chandigarh (72.2). After the UT's Haryana state having the highest (71.1) prevalence followed by Jharkhand (70.1), Madhya Pradesh (69.0), Bihar (63.5) and Uttar Pradesh (63.5). The lowest prevalence of anemia is observed in Mizoram state (19.6) followed by Manipur (24.0), Nagaland (26.6), Assam (35.9) and Kerala (36.0). With the pattern of distribution, we can observe northern states having the highest prevalence and lowest among the north-eastern states of India. The clustering of the disease was more in the Central region and some of the states of the Eastern and western region. In the South, the higher prevalence of anemia was observed in Telangana and Karnataka.

Map 2 shows the district wise prevalence of anemia among children of 6-59 months. The top five district of having highest prevalence of anemia among children are Leh (95.8), Lahul \& Spiti (94.9), Kargil (87.6), Banswara (84.4), and Dadra \& Nagar Haveli (84.4) whereas bottom five lowest prevalence district of anemia are Champhai (7.9), Aizawl (11.1), Mokokchung (13.0), Phek (13.2) and Longleng (14.9). Among the top five districts two districts Leh and Kargil comes in Jammu \& Kashmir, Lahul \& Spiti district comes in Himachal Pradesh and Banswara district comes in the Rajasthan state of India. Champhai and Aizawl districts come in Mizoram and Mokokchung, Phek and Longleng come in Nagaland state. We can see in the district of the northern state having the highest prevalence of anemia whereas districts in the north-east state having the lowest prevalence of anemia among children of 6-59 months.

\subsection{Prevalence of anemia by background characteristics among children aged 6-59 months}

The bivariate association between anemia status of children aged 6-59 months and predictors are shown in Table 2. The overall prevalence of anemia was 59\% in India among 6-59 months in children. The prevalence of anemia among children aged 6-59 months was $69 \%$ for children under $6-11$ months, $48 \%$ of children were anemic of aged $36+$ months. Hence, as the age of children increases the prevalence of anemia among children decreased. Sex of the children, full immunization and currently working status was the only explanatory variable that had an insignificant association with anemia among children aged 6-59 months. The prevalence of anemia was higher among multiple births (63\%) compared to mothers who give single birth with $59 \%$ respectively. Anemia is more prevalent among children born very small at the time of birth compared to children in size small and average/large.
In the present study, Diarrhoea and fever have shown a significant association with anemia. In addition, not using bed nets shows association with anemia. The higher the age of the mother, the lower is the prevalence of anemia among children. High parity children are more anemic. The wealth index shows a significant association with anemia status among children aged between 6 and 59 months. It indicates that children from the poorest $(65 \%)$ families followed by poorer $(60 \%)$ were more exposed to anemia compared to children from richest (52\%) families. Mothers having no exposure to media have a higher prevalence of anemic children compared to the mothers have partial or full exposure to media, with findings showing a significant association. The source of drinking water and latrine facility had a significant association with anemia status among children aged between 6 and 59 months in India. The proportion of anemia status was also high for children who didn't use improved water. Children, who used improved latrine facility, had a lower prevalence of anemia (55\%) than children who did not use improved latrine facility (62.1\%). In India, the prevalence of anemia varied from one region to another, shows significant association among children aged between 6 and 59 months. The highest proportion of anemia status was observed in the central region (63\%) followed by North (61\%), East (60\%), West (57\%), South (54\%) and the lowest percentage that was recorded in Northeast region (37\%). Accordingly, nearly $60 \%$ of anemic children resided in rural areas with relatively lesser percentages (56\%) resided in urban areas. The prevalence of anemia is higher where community education is low and vice versa. It is important to note that ethnic and religion fractionalization index, have observed to be significantly associated with the prevalence of anemia in the bivariate analysis. The higher levels of community ethnic and religious concentration decrease the prevalence of anemia among children.

\subsection{Association of anemia with different risk factors at different levels: results of the multilevel analysis}

\subsubsection{Fixed effect model}

This study used multilevel modelling analysis on anemia using DHS dataset, and the results showed in Table 3 that there was a significant variation of anemia across clusters in India. The model 1 is a null model. Model 2 shows that children aged 12-35 months were $(\mathrm{OR}=1.13$; 95\% CI: $0.99-1.28)$ significantly more likely to have anemia as compared to 6-11 months children. The likelihood of being anemic for girl child was 1.07 times in model 2 and 1.06 in model 3 higher (07\% more likely) than boy child with significant results. Anemia was also found to be more likely among children of small size $(\mathrm{OR}=1.34$ and 1.11$)$ in model 2 and model 3 with 1.24 and 1.05 times more likely among children of average/large size in model 2 and model 3 , though the results were significant only in model 2 . In model 2, another variable significantly associated with childhood anemia was diarrhoea and use of bed net. Children suffered from diarrhoea were $22 \%$ more likely to have anemia while the use of bed net decreased the likelihood of anemia by $16 \%$. After including all the variables in model 3 , children suffered from diarrhoea was $17 \%$ more likely to be anemic, but the use of bed net became insignificant in model 3. Mother's age was strongly associated with the prevalence of anemia. The risk of anemia among children was 0.84 and 0.82 less likely in age group 25-34 and 35-49 years age group compared to 15-24 years age group. The findings were significant.

The odds of Mother's parity of $2-3$ and above 4 were significantly associated with anemia. In model $2,17 \%$ of parity $2-3$ and $27 \%$ of parity 4 and above were more likely to have anemic children than mother with first parity, while in model 3 , it was $11 \%$ (2-3 parity) and $14 \%(4+$ parity) respectively. No and partial media exposure are significantly more likely to associate as compared to full media exposure in both model 2 and model 3 . The less exposure to mass media among mothers increased the likelihood of anemia among children.

In model 3, household and community variables are taken in the 


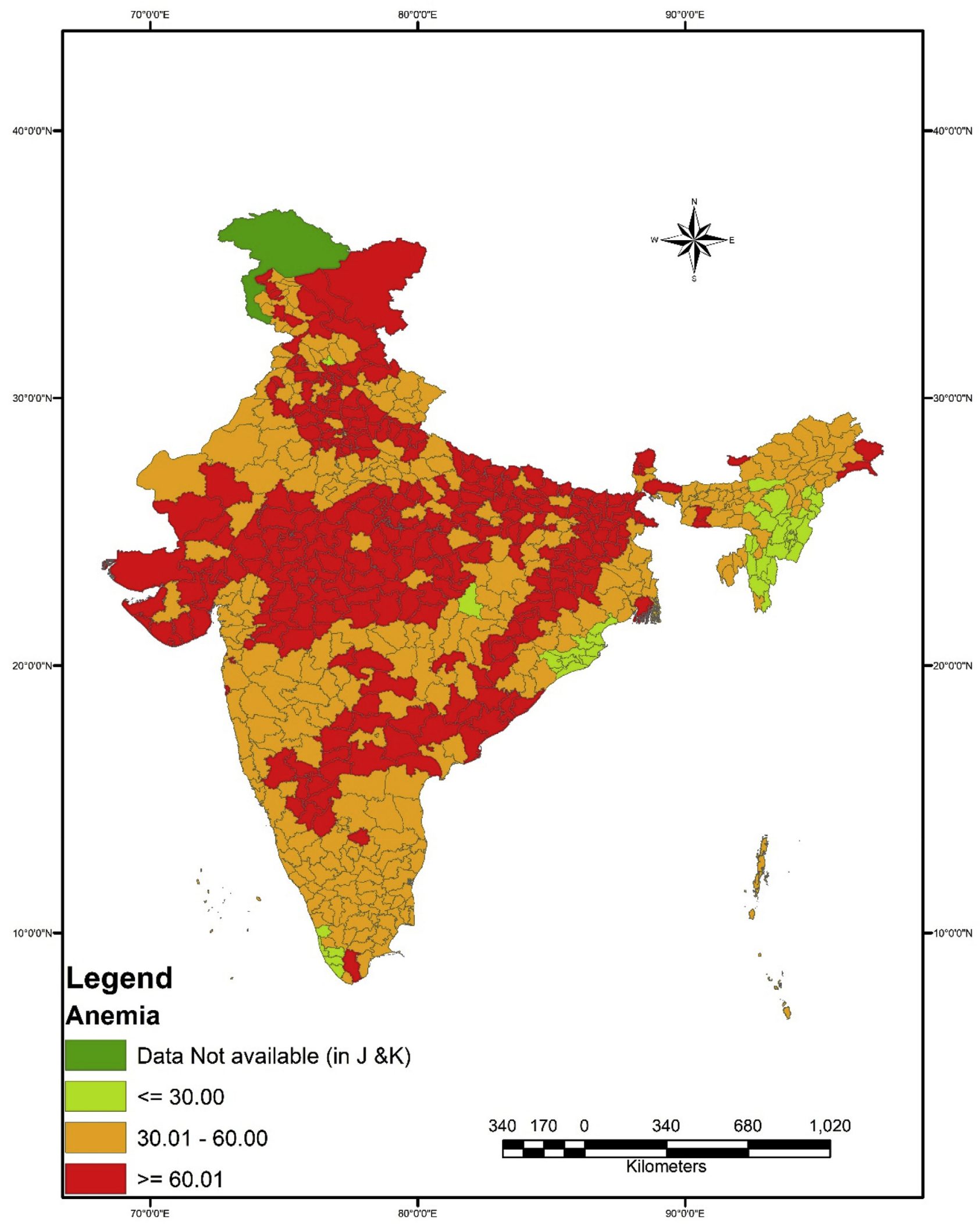

Map 1. Prevalence of anemia at the State-level in India among children aged 6-59 months.

analysis. In India, children living in households with medium and poor living standards had a higher risk of anemia than children living in households with high living standards. The odds of anemia is higher among household used unimproved latrine facility. The odds of having anemic children is less in the northeast region $(\mathrm{OR}=0.47)$ with significant association compared to the south region. The Northern region is highly likely to experience anemia among children compared to the Southern region. Community education was significantly associated with anemia in India $(\mathrm{OR}=0.91 ; 95 \% \mathrm{CI}=0.84-0.98)$. The clusters level of ethnic fractionalization was 0.91 times less likely while 


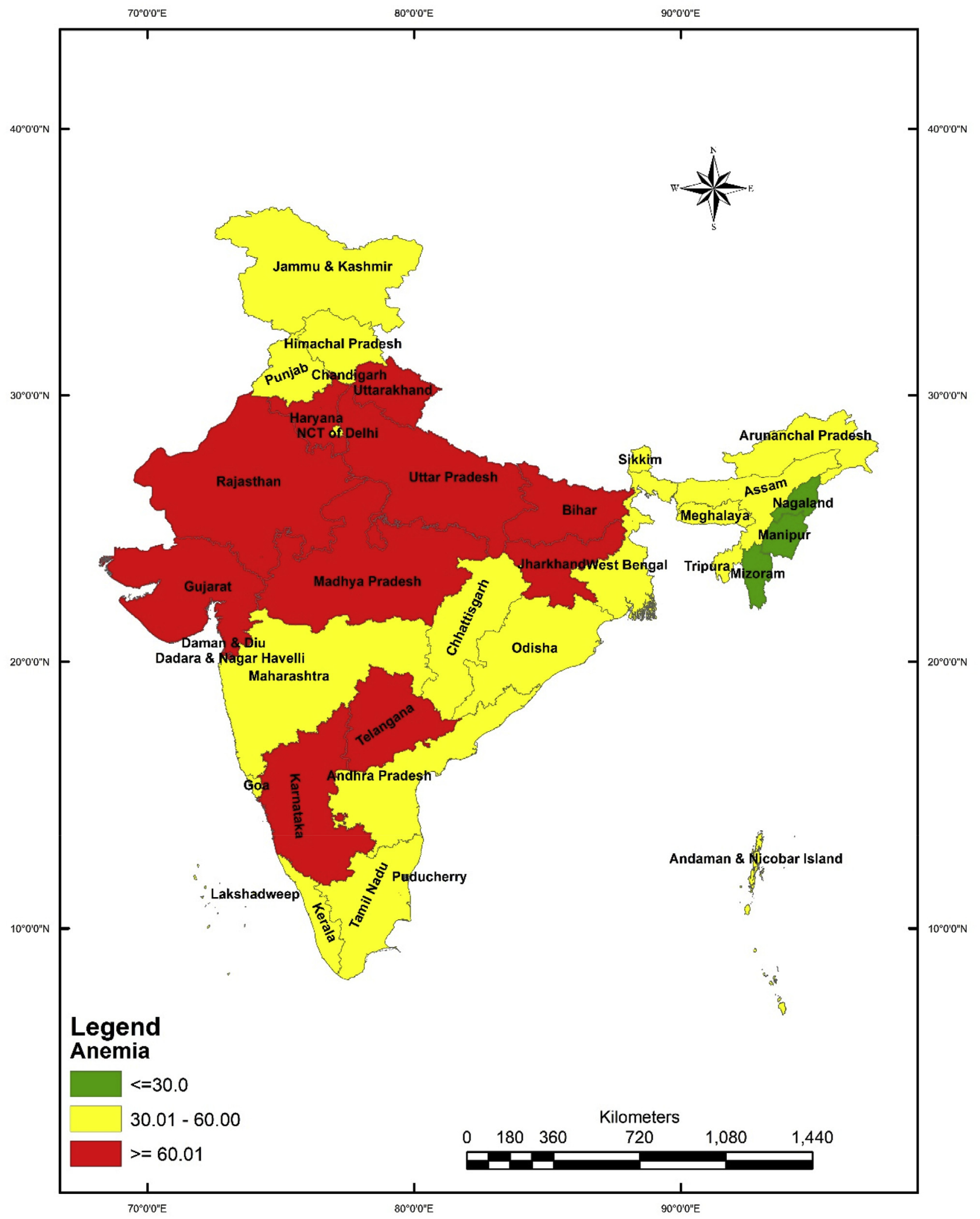

Map 2. District wise Prevalence of anemia among children aged 6-59 months in India.

religion fractionalization was 1.08 times more likely to have anemic children compared to non-anemic children, showing a significant association. The lower level of community ethnic and religious concentration are significantly increased the likelihood of anemia among children.

\subsubsection{Random intercept model}

Table 4 shows the results of the random intercept model, which explored the variation in the prevalence of anemia at the district and community (PSU) levels in India. The empty model (null model) showed that childhood anemia was not random across the communities 
Table 2

Prevalence of Anemia among children 6-59 Months with Chi-Square Results.

\begin{tabular}{|c|c|c|}
\hline Background Variables & Prevalence of Anemia & $\mathrm{N}$ \\
\hline Child Age & $P=0.000$ & \\
\hline $6-11$ & 68.6 & 22012 \\
\hline $12-35$ & 66.5 & 93059 \\
\hline $36+$ & 48.6 & 94424 \\
\hline Sex & $P=0.693$ & \\
\hline Boy & 58.5 & 109087 \\
\hline Girl & 58.8 & 100408 \\
\hline Type of Birth & $P=0.000$ & \\
\hline Single & 58.6 & 206651 \\
\hline Multiple & 62.6 & 2844 \\
\hline Size of Child & $P=0.000$ & \\
\hline Very Small & 63.5 & 5787 \\
\hline Small & 61.0 & 18434 \\
\hline Average and above & 58.3 & 180652 \\
\hline Diarrhoea & $P=0.000$ & \\
\hline No & 58.0 & 190639 \\
\hline Yes & 65.0 & 18856 \\
\hline Fever & $P=0.000$ & \\
\hline No & 58.2 & 181934 \\
\hline Yes & 61.6 & 27561 \\
\hline Bed Net & $P=0.000$ & \\
\hline No & 59.9 & 120388 \\
\hline Yes & 56.7 & 89107 \\
\hline Full Immunization & $P=0.466$ & \\
\hline Yes & 56.8 & 114819 \\
\hline No & 60.0 & 17361 \\
\hline Age of Mother & $P=0.000$ & \\
\hline $15-24$ & 61.8 & 64163 \\
\hline $25-34$ & 57.3 & 123372 \\
\hline $35-49$ & 56.1 & 21960 \\
\hline Parity & $P=0.000$ & \\
\hline First parity & 55.6 & 76761 \\
\hline 2-3_Parity & 59.5 & 98782 \\
\hline $4+$ above & 64.0 & 33952 \\
\hline Currently Working & $P=0.807$ & \\
\hline No & 58.3 & 29926 \\
\hline Yes & 58.3 & 6584 \\
\hline Wealth Index & $P=0.000$ & \\
\hline Richest & 51.9 & 28147 \\
\hline Richer & 54.5 & 35001 \\
\hline Middle & 59.1 & 41853 \\
\hline Poorer & 59.9 & 49361 \\
\hline Poorest & 64.1 & 55133 \\
\hline Mass Media & $P=0.000$ & \\
\hline Full Exposure & 53.3 & 14656 \\
\hline Partial Exposure & 57.2 & 136448 \\
\hline No Exposure & 63.7 & 58391 \\
\hline Drinking Water & $P=0.000$ & \\
\hline Improved & 58.6 & 175779 \\
\hline Unimproved & 59.0 & 33716 \\
\hline Latrine facility Type & $P=0.000$ & \\
\hline Improved & 54.9 & 101638 \\
\hline Unimproved & 62.1 & 107857 \\
\hline Region & $P=0.000$ & \\
\hline South & 54.4 & 20547 \\
\hline West & 56.8 & 14659 \\
\hline Northeast & 36.9 & 29312 \\
\hline East & 59.5 & 44365 \\
\hline Central & 62.9 & 60873 \\
\hline North & 61.3 & 39739 \\
\hline Place of Residence & $P=0.000$ & \\
\hline Urban & 56.1 & 49826 \\
\hline Rural & 59.6 & 159669 \\
\hline Community Education & $P=0.000$ & \\
\hline Low & 64.3 & 91449 \\
\hline High & 54.6 & 118046 \\
\hline Ethnic Fractionalization Index & $P=0.000$ & \\
\hline Totally Homogeneous & 56.4 & 51490 \\
\hline Not Homogeneous & 59.2 & 158005 \\
\hline Religion Fractionalization Index & $P=0.000$ & \\
\hline Totally Homogeneous & 58.5 & 139781 \\
\hline Not Homogeneous & 58.9 & 69714 \\
\hline Total & 58.7 & 209495 \\
\hline
\end{tabular}

and districts. The variance partition coefficient (VPC) for the empty model at the district and community levels contributed $12 \%$ and $20 \%$ respectively to the total variation in the prevalence of anemia. The results revealed that the variation in the prevalence of anemia was attributable to the community-level factors. The full model, after having been adjusted for the individual and community-level variables, shows that the variation in childhood anemia across the districts $(8.5 \%)$ and communities (16.8\%) was decreasing but was, nevertheless, statistically significant for communities as well as districts. A high value of VPC would reflect a high clustering of anemia prevalence within communities plus a high neighbourhood effect on individual risk of anemia. The remaining percentage of variability is due to the variation in the respondents/households and other unknown factors. Thus, there remains some regional level variance unaccounted for in the model. Similarly, the median odds ratio (MOR) confirmed the geographical variation in the prevalence of anemia in India. The MOR for anemia was 2.37 at the community level and 1.95 at the district level in the empty model, indicating that the prevalence of anemia was higher at the community level. After the model was adjusted for all the factors, the variation in anemia decreased to a MOR of 2.17 at the community level and to a MOR of 1.73 at the district level. This shows that after the model having been adjusted for all the factors, the effect was still statistically significant in the full model.

\section{Discussion}

Detection of risk factors is fundamental for planning and implementation of programs to eradicate childhood anemia, especially in those groups where prevalence is very high. Childhood anemia is found to be a major public health challenge in India with a high prevalence of nearly sixty percentages. Several studies have recorded the higher prevalence of anemia including India and in other countries. ${ }^{47-50}$ The study confirmed prevalence estimates differed by some key variables associated with anemia, as well as regional variation. These regional differences could be due to inadequate dietary intake; access to health care centres; and infectious disease risk. ${ }^{51}$

This study reveals that the prevalence of anemia amongst young was higher than in the overall population. The result showed as the age increases the risk of anemia among children decreases. This could likely be due to the higher incidences of maternal micronutrient deficits as well as low concentrations of iron in breast milk due to anemia in mothers, insufficient to meet the daily requirements of iron for the children. The likelihood of anemia is significantly higher among children less than two years old compared to those aged 2-5 years may be due to the iron intake which improves with age in the form varied diet including haemoglobin rich foods. Literature have reported a similar trend that the risk of having anemia prevalence decreases with age. ${ }^{33,49,52,53}$ The prevalence of anemia showed a homogeneous distribution according to sex (58.5\% boy and $58.8 \%$ girl). However, few studies have found a higher prevalence of anemia in boys than in girls. $^{54,55}$ The likelihood of children being anemic, residing in poorest households appeared to increase the risk of childhood anemia when compared with other wealth index individuals. The finding is consistent with previous studies ${ }^{50,56,57}$ and plausibly reflecting better household nutritional status. ${ }^{58}$ In addition, even after controlling for drinking water and sanitation facilities, Diarrhoea shows significant association with anemia. ${ }^{59}$ Diarrhoeal illness is prone among children of lower socio-economic status. It is associated with a deficiency in iron content and decreased absorption of other micronutrients deficiencies which is needed to maintain normal haemoglobin status. ${ }^{44,60-63}$ In contrast with our findings, conclusions from other studies also indicate that women with low educational level were more likely to be anemic children, shows a significant association between education and anemia. ${ }^{64-66}$ However, the current study didn't consider the prevalence of anemia among children of anemic mothers as mothers and children can share common socioeconomic status, home environment, and dietary 
Table 3

Results for multilevel analysis of the prevalence of childhood Anemia, India 2015-16.

\begin{tabular}{|c|c|c|c|c|c|c|c|c|c|c|c|}
\hline \multirow[t]{2}{*}{ Background Variables } & \multicolumn{4}{|l|}{ Model 1} & \multicolumn{3}{|l|}{ Model 2} & \multicolumn{4}{|c|}{ Model 3} \\
\hline & Empty Model & SE & CI & Odds & SE & P Value & CI & Odds & SE & P Value & CI \\
\hline \multicolumn{12}{|l|}{ Child Age } \\
\hline \multicolumn{12}{|l|}{$6-11^{\oplus}$} \\
\hline $12-35$ & & & & 1.13 & 0.07 & 0.061 & $0.99-1.28$ & 1.01 & 0.07 & 0.937 & $0.88-1.15$ \\
\hline $36+$ & & & & 0.48 & 0.03 & 0.000 & $0.42-0.54$ & 0.42 & 0.03 & 0.000 & $0.37-0.48$ \\
\hline \multicolumn{12}{|l|}{ Sex } \\
\hline Boy $^{\circledast}$ & & & & & & & & & & & \\
\hline Girl & & & & 1.07 & 0.03 & 0.017 & $1.01-1.14$ & 1.06 & 0.03 & 0.040 & $1.00-1.13$ \\
\hline Type of Birth & & & & & & & & & & & \\
\hline Single ${ }^{\circledR}$ & & & & & & & & & & & \\
\hline Multiple & & & & 1.18 & 0.16 & 0.220 & $0.90-1.54$ & 1.16 & 0.16 & 0.268 & $0.89-1.52$ \\
\hline Size of Child & & & & & & & & & & & \\
\hline Very Small ${ }^{\circledast}$ & & & & & & & & & & & \\
\hline Small & & & & 1.34 & 0.12 & 0.001 & $1.13-1.58$ & 1.11 & 0.11 & 0.249 & $0.93-1.34$ \\
\hline Average and above & & & & 1.24 & 0.09 & 0.002 & $1.08-1.42$ & 1.05 & 0.08 & 0.575 & $0.89-1.22$ \\
\hline Diarrhoea & & & & & & & & & & & \\
\hline $\mathrm{No}^{\circledast}$ & & & & & & & & & & & \\
\hline Yes & & & & 1.22 & 0.07 & 0.000 & $1.09-1.37$ & 1.17 & 0.07 & 0.006 & $1.05-1.31$ \\
\hline Fever & & & & & & & & & & & \\
\hline $\mathrm{No}^{\circledast}$ & & & & & & & & & & & \\
\hline Yes & & & & 0.99 & 0.05 & 0.897 & $0.91-1.09$ & 0.98 & 0.05 & 0.614 & $0.89-1.07$ \\
\hline Bed Net & & & & & & & & & & & \\
\hline $\mathrm{No}^{\oplus}$ & & & & & & & & & & & \\
\hline Yes & & & & 0.84 & 0.03 & 0.000 & $0.78-0.91$ & 0.95 & 0.04 & 0.197 & $0.88-1.03$ \\
\hline Full Immunization & & & & & & & & & & & \\
\hline Yes $^{\circledast}$ & & & & & & & & & & & \\
\hline No & & & & 1.09 & 0.06 & 0.103 & $0.98-1.21$ & 1.07 & 0.06 & 0.192 & $0.97-1.19$ \\
\hline Age of Mother & & & & & & & & & & & \\
\hline $15-24^{\circledR}$ & & & & & & & & & & & \\
\hline $25-34$ & & & & 0.84 & 0.03 & 0.000 & $0.78-0.91$ & 0.87 & 0.03 & 0.000 & $0.81-0.94$ \\
\hline $35-49$ & & & & 0.82 & 0.05 & 0.002 & $0.73-0.93$ & 0.90 & 0.06 & 0.085 & $0.79-1.02$ \\
\hline Parity & & & & & & & & & & & \\
\hline First parity ${ }^{\circledR}$ & & & & & & & & & & & \\
\hline 2-3 parity & & & & 1.17 & 0.04 & 0.000 & $1.09-1.25$ & 1.11 & 0.04 & 0.003 & $1.04-1.19$ \\
\hline $4+$ above & & & & 1.27 & 0.07 & 0.000 & $1.14-1.41$ & 1.14 & 0.07 & 0.026 & $1.01-1.27$ \\
\hline Currently Working & & & & & & & & & & & \\
\hline $\mathrm{No}^{\circledast}$ & & & & & & & & & & & \\
\hline Yes & & & & 1.03 & 0.04 & 0.484 & $0.95-1.12$ & 1.01 & 0.04 & 0.842 & 0.93-1.09 \\
\hline Mass Media & & & & & & & & & & & \\
\hline Full Exposure ${ }^{\oplus}$ & & & & & & & & & & & \\
\hline Partial Exposure & & & & 1.36 & 0.07 & 0.000 & $1.22-1.52$ & 1.18 & 0.07 & 0.004 & $1.06-1.32$ \\
\hline No Exposure & & & & 1.73 & 0.11 & 0.000 & $1.53-1.97$ & 1.27 & 0.09 & 0.001 & $1.10-1.46$ \\
\hline Wealth Index & & & & & & & & & & & \\
\hline Richest $^{\circledast}$ & & & & & & & & & & & \\
\hline Richer & & & & & & & & 1.15 & 0.06 & 0.010 & $1.03-1.27$ \\
\hline Middle & & & & & & & & 1.31 & 0.07 & 0.000 & $1.17-1.46$ \\
\hline Poorer & & & & & & & & 1.42 & 0.09 & 0.000 & $1.25-1.61$ \\
\hline Poorest & & & & & & & & 1.66 & 0.13 & 0.000 & $1.43-1.93$ \\
\hline Drinking Water & & & & & & & & & & & \\
\hline Improved ${ }^{\circledast}$ & & & & & & & & & & & \\
\hline Unimproved & & & & & & & & 0.97 & 0.05 & 0.455 & $0.88-1.06$ \\
\hline Latrine facility Type & & & & & & & & & & & \\
\hline Improved $^{\circledR}$ & & & & & & & & & & & \\
\hline Unimproved & & & & & & & & 1.08 & 0.05 & 0.062 & $1.00-1.18$ \\
\hline Region & & & & & & & & & & & \\
\hline South ${ }^{\circledast}$ & & & & & & & & & & & \\
\hline West & & & & & & & & 1.43 & 0.16 & 0.001 & $1.15-1.79$ \\
\hline Northeast & & & & & & & & 0.47 & 0.05 & 0.000 & $0.38-0.58$ \\
\hline East & & & & & & & & 1.10 & 0.11 & 0.355 & $0.90-1.34$ \\
\hline Central & & & & & & & & 1.49 & 0.14 & 0.000 & $1.24-1.78$ \\
\hline North & & & & & & & & 1.81 & 0.17 & 0.000 & $1.51-2.17$ \\
\hline Place of Residence & & & & & & & & & & & \\
\hline Urban ${ }^{\circledast}$ & & & & & & & & & & & \\
\hline Rural & & & & & & & & 0.97 & 0.04 & 0.528 & $0.89-1.06$ \\
\hline Community Educatio & & & & & & & & & & & \\
\hline Low $^{\circledast}$ & & & & & & & & & & & \\
\hline High & & & & & & & & 0.91 & 0.04 & 0.016 & $0.84-0.98$ \\
\hline Ethnic Fractionalizat & ndex & & & & & & & & & & \\
\hline Totally Homogeneous & & & & & & & & & & & \\
\hline Not Homogeneous & & & & & & & & 1.08 & 0.05 & 0.093 & $0.99-1.17$ \\
\hline Religion Fractionaliz & Index & & & & & & & & & & \\
\hline Totally Homogeneous & & & & & & & & & & & \\
\hline
\end{tabular}


Table 3 (continued)

\begin{tabular}{|c|c|c|c|c|c|c|c|c|c|c|c|}
\hline \multirow[t]{2}{*}{ Background Variables } & \multicolumn{4}{|l|}{ Model 1} & \multicolumn{3}{|l|}{ Model 2} & \multicolumn{4}{|c|}{ Model 3} \\
\hline & Empty Model & SE & CI & Odds & SE & P Value & CI & Odds & SE & P Value & $\mathrm{CI}$ \\
\hline Not Homogeneous & & & & & & & & 1.07 & 0.04 & 0.096 & $0.99-1.15$ \\
\hline
\end{tabular}

Note: ${ }^{\circledR}$ Reference category, significance level: $*(\mathrm{p}<0.10), * *(\mathrm{p}<0.05), * * *(\mathrm{p}<0.01)$, CI: Confidence Interval, SE: Standard Error.

Table 4

Results for Random Intercept model for the prevalence of childhood Anemia at cluster level by multilevel logistic regression, India, 2015-16.

\begin{tabular}{|c|c|c|c|c|c|c|c|c|c|}
\hline Random Effect Part & Model 1 & SE & $95 \% \mathrm{CI}$ & Model 2 & SE & $95 \% \mathrm{CI}$ & Model 3 & SE & $95 \% \mathrm{CI}$ \\
\hline \multicolumn{10}{|l|}{ Variance (SE) } \\
\hline Dist. & 0.497 & 0.029 & $0.44-0.55$ & 0.49 & 0.04 & $0.42-0.56$ & 0.34 & 0.03 & $0.28-0.39$ \\
\hline PSU & 0.326 & 0.008 & $0.31-0.34$ & 0.33 & 0.03 & $0.27-0.39$ & 0.33 & 0.03 & $0.26-0.39$ \\
\hline \multicolumn{10}{|l|}{ VPC(\%) } \\
\hline Level 3 (Dist.) & 12.1 & & & 11.9 & & & 8.5 & & \\
\hline Level 2 (PSU) & 20.0 & & & 19.9 & & & 16.8 & & \\
\hline \multicolumn{10}{|c|}{ Median odds Ratio (MOR) } \\
\hline MOR $_{\text {Dist }}$ & 1.95 & & & 1.94 & & & 1.73 & & \\
\hline $\mathrm{MOR}_{\mathrm{PSU}}$ & 2.37 & & & 2.36 & & & 2.17 & & \\
\hline
\end{tabular}

Note: CI: Confidence Interval, SE: Standard Error, VPC: Variance Partition Coefficient.

conditions which may reflect the common nutritional status of the household. ${ }^{21,65,66}$

\section{Conclusion}

In summary, our study demonstrates that the prevalence of anemia is more prevalent among children aged 6-59 months in India was a severe public health problem. Our findings provide several insights into the population. Children aged 12-35 months, girl child, children having diarrhoea, mothers in the age group of 15-24, high parity children and low exposure to mass media among mother were high risk individual factors of anemia among children. The study showed low community education as a major determinant of anemia among children. It is also found that low community ethnic and religious concentration increased the chances of anemia among children. The socioeconomic status of the family and iron diet deficiency and other essential nutrients are of great importance in the development of anemia. Thus, the government should pay more attention to significant factors like wealth index, availability of pure drinking water and sanitation facilities as these are the most influential factors that should be enhanced anyway. Spatial variability of state and district of anemia prevalence are the sole findings of this paper. ${ }^{67}$ Hence, the government should give special attention to households having children of aged 6-59 months living in these high anemic prevalence regions. The government should also focus on providing information to new mothers on adequate nutrition for their young babies. Special emphasis on addressing iron and other micronutrient deficiencies, should be a prime focus to reduce childhood anemia under public health policy and intervention programmes. This research, based on recent Indian DHS will undoubtedly contribute to a greater comprehension of the determinants of anemia at the individual, and community levels.

\subsection{Limitations of the study}

There are a few limitations to this study. First, this analysis used cross-sectional surveys, it was not possible to follow Haemoglobin levels in an individual. Thus, our study fails to determine any causal relation-ships and direction of causality between socioeconomic status and anemia which may be bidirectional. However, the surveys are nationally representative and it uses consistent methodologies in the assessment and classification of anemia across time, the estimates of anemia prevalence is likely to represent a population-based estimates. Secondly, relationships between children's dietary iron intake and supplementation were not possible due to the absence of data in the DHS surveys as it is well documented in few kinds of literature that iron-deficiency anemia contributes to approximately half of the total anemia population. ${ }^{68-70}$

\subsection{Policy implications}

Over time, there has been an increasing trend seen among anemic women of reproductive age. Anemia remains a major public health problem in the country, thus have a number of implications for both policy makers and health professionals. Among all other developing countries, India was the first country to establish a national anemia programme in 1970 named as Nutritional Anemia Prophylaxis Programme which was constituted by the Ministry of Health and Family Welfare. It aimed to target specific populations who are at high risk of anemia, namely pregnant women, lactating women and preschool children between 1 and 5 years of age. ${ }^{71}$ Later, anemia prevention and control came into existence in health strategies and programmes. An ambitious time-bound goal set out in 11th Five Year Plan to reducing anemia among girls and by women $50 \%$ by $2012 .{ }^{72}$ However, due to variations in states, this goal is unlikely to be reached. Improved capacity to translate policies relating to health and nutrition may in part explain the performance in responding to anemia in this population. Enhancing the usage of the present approach reaction to anemia prevention and control, together with addressing knowledge gaps behind these expanding patterns, will enhance our capacity to address the multifactorial aetiology of anemia within the Indian population.

\section{Availability of data and materials}

The datasets generated and/or analyzed during the current study are available in the DHS Program repository, http://dhsprogram.com/ data/available-datasets. cfm.

\section{Ethics approval and consent to participate}

Informed consent was obtained at the beginning of each interview and the authors sought permission from the DHS program for the use of the data.

\section{Authors' contributions}

MD contributed to the conceptualization and design of the study. 
MD, MB, LP acquired the data, conducted the analysis and interpreted the results. MD and LP drafted the article. MD, HC, PD revised the draft critically for important intellectual content. All authors reviewed and approved the final version of the manuscript.

\section{Funding}

We have not received any funding or received grant from any funding agencies for this study.

\section{Declaration of competing interest}

The authors declare that they have no competing interests.

\section{Acknowledgments}

The authors are thankful to the Demographic Health Survey (DHS), for providing the NFHS-4 data upon request. Data can be obtained after free registration on the site www.dhsprogram.com and by submitting the data request form. The data set is accessible to anyone and is not allowed to use for commercial purposes.

\section{References}

1. Benoist BD, McLean E, Egll I, Cogswell M. Worldwide Prevalence of Anemia 1993-2005: WHO Global Database on Anemia. Worldwide Prevalence of Anemia 1993-2005: WHO Global Database on Anemia. 2008; 2008.

2. Petry N, Olofin I, Hurrell RF, et al. The proportion of anemia associated with iron deficiency in low, medium, and high human development index countries: a systematic analysis of national surveys. Nutrients. 2016 Nov 2;8(11):693.

3. Soemantri AG, Pollitt E, Kim I. Iron deficiency anemia and educational achievement. Am J Clin Nutr. 1985 Dec 1:42(6):1221-1228.

4. Pollitt E, Hathiral P, Kotchabhakdi NJ, Missell L, Valyasevi A. Iron deficiency and educational achievement in Thailand. Am J Clin Nutr. 1989 Sep 1;50(3):687-697.

5. World Health Organization. Iron Deficiency Anaemia: Assessment, Prevention and Control. A Guide for Programme Managers. Geneva: World Health Organization; 2001; 2015 World Health Organization (WHO). http://www.who.int/nutrition/ publications/en/ida_assessment_prevention_control.pdf.

6. World Health Organization. Global Technical Strategy for Malaria 2016-2030. World Health Organization; 2015 Nov 4.

7. IIPS MI, Macro OR. National Family Health Survey (NFHS-3), 2005-2006. Mumbai: IIPS; 2007.

8. Pasricha SR, Flecknoe-Brown SC, Allen KJ, et al. Diagnosis and management of iron deficiency anemia: a clinical update. Med J Aust. 2010 Nov 1;193(9):525-532.

9. McLean E, Coqswell M, Egli I, Wojdyla D, de Benoist B. Worldwide prevalence of anemia, WHO vitamin and mineral nutrition information system, 1993-2005. Publ Health Nutr. 2009;12(4):444-454.

10. Jain N, Jain VM. Prevalence of anemia in school children. Med Pract Rev. 2012;3:1-4.

11. World Bank. Poverty and Income. The Poverty Group; 2004http://devdata.worldbank. org/.hnpstats./pvd.asp.

12. Pasricha SR, Black J, Muthayya S, et al. Determinants of anemia among young children in rural India. Pediatrics. 2010;126(1):140-149.

13. Makhoul Z, Taren D, Duncan B, et al. Risk factors associated with anemia, iron deficiency and iron deficiency anemia in rural Nepali pregnant women. Southeast Asian J Trop Med Publ Health. 2012;43(3):735-746.

14. Verhoeff FH, Brabin BJ, Chimsuku L, Kazembe P, Broadhead RL. An analysis of the determinants of anemia in pregnant women in rural Malawi: a basis for action. Ann Trop Med Parasitol. 1999;93:119-133.

15. Ayoya MA, Spiekermann-Brouwer GM, TrORe AK, Stoltzfus RJ, Garza C. Determinants of anemia among pregnant women in Mali. Food Nutr Bull. 2006;27:3-11.

16. Christian P, West Jr KP, Khatry SK, et al. Night blindness of pregnancy in Nepal: nutritional and health risks. Int J Epidemiol. 1998;27:231-237.

17. Van Den Broek NR, Letsky EA. Etiology of anemia in pregnancy in south Malawi. Am J Clin Nutr. 2000:S247-S256.

18. Brabin BJ, Premji Z, Verhoeff F. An analysis of anemia and child mortality. J Nutr. 2001:131(2S-2) 636S-48S

19. Pita GM, Jimenez S, Basabe B, et al. Anemia in children under five years old in eastern Cuba, 2005-2011. Med Rev. 2014;16(1):16-23.

20. Stoltzfus RJ. Iron-deficiency anemia: reexamining the nature and magnitude of the public health problem. Summary: implications for research and programs. J Nutr. 2001;131(2):697S-700S.

21. Oliveira MAA, Osorio MM, Raposo MCF. Socioeconomic and dietary risk factors for anemia in children aged 6 to 59 months. J Pediatr. 2007;83(1):39-46.

22. Osorio MM, Lira PI, Ashworth A. Factors associated with Hb concentration in children aged 6-59 months in the state of Pernambuco, Brazil. Br J Nutr. 2004:91:307-315.

23. Sanou D, Ngnie-Teta I. Risk Factors for Anemia in Preschool Children in SubSaharan
Africa. Anemia978-953-51-0138-3; 2012 InTech.

24. Neuman NA, Tanaka OY, Szarfarc SC, Guimaraes PRV, Victora C. Prevalencia e fatores de risco para anemia no Sul do Brasil. Rev Saude Publica. 2000;34(1):56-63.

25. Osorio MM. Determinant factors of anemia in children. $J$ Pediatr. 2002;78(4):269-278.

26. Best C, Neufingerl N, Van Geel L, van den Briel T, Osendarp S. The nutritional status of school-aged children: why should we care? Food Nutr Bull. 2010 Sep;31(3):400-417.

27. Maryam F, Hina R, Khawaja T, Fatima A, Mariam Z. Factors responsible for iron deficiency anemia in children. J Biomed Sci Res. 2011;3(1):308-314.

28. Desalegn A, Mossie A, Gedefaw L. Nutritional iron deficiency anemia: magnitude and its predictors among school age children, southwest Ethiopia: a community based cross-sectional study. PloS One. 2014 Dec 1;9(12) e114059.

29. Goswmai S, Das KK. Socio-economic and demographic determinants of childhood anemia. J Pediatr. 2015 Sep 1;91(5):471-477.

30. Choi HJ, Lee HJ, Jang HB, et al. Effects of maternal education on diet, anemia, and iron deficiency in Korean school-aged children. BMC Publ Health. 2011 Dec;11(1):870

31. Janus J, Moerschel SK. Evaluation of anemia in children. Am Fam Physician. 2012;81(12):1462-1471.

32. Bizzarro MJ, Colson E, Ehrenkranz RA. Differential diagnosis and management of anemia in the newborn. Pediatr Clin. 2004;51(4):1087-1107.

33. Osorio MM, Lira PIC, Batista-Filho M. Prevalence of anemia in children 6-59 months old in the state of Pernambuco, Brazil. Rev Panam Salud Publ/Pan Am J Publ Health. 2001;10(2):101-107.

34. Torres MAA, Sato K, Queiroz SS. Anemia em crianças menores de dois anos atendidas nas unidades basicas de saude no Estado de São Paulo, Brasil. Rev Saude Publica. 1994;28(1):290-294.

35. Emond AM, Hawkins N, Pennock C, Golding J. Haemoglobin and ferritin concentrations in infants at 8 months of age. Arch Dis Child. 1996;74:36-39.

36. Michaelsen KF, Milman N, Samuelson G. A longitudinal study of iron status in healthy Danish infants: effects of early iron status, growth velocity and dietary factors. Acta Paediatr. 1995;84(1):1034-1044.

37. Kuate-Defo B. Modelling hierarchically clustered longitudinal survival processes with applications to childhood mortality and maternal health. Can Stud Popul. 2001;28(2):535-561.

38. Ngnie-Teta I, Kuate-Defo B, Receveur O. Multilevel modelling of sociodemographic predictors of various levels of anemia among women in Mali. Publ Health Nutr. 2009;12(9):1462-1469.

39. Sidhu S, Kumari K, Uppal M. Prevalence of anemia in Bazigar (ex-nomadic tribe) preschool children of Punjab. J Hum Ecol 2007 Apr 1;21(4):265-267.

40. Jai Prabhakar SC, Gangadhar MR. Prevalence of anemia in Jenukuruba primitive tribal children of Mysore district, Karnataka. Anthropol. 2009;11(1):49-51.

41. International Institute for Population Sciences (IIPS) \& ORC MACRO. National Family Health Survey (NFHS-3), 2005-06: India. vol. I. Mumbai: IIPS; 2007.

42. Gehring H, Hornberger C, Dibbelt L, et al. Accuracy of point-of-care-testing (POCT) for determining haemoglobin concentrations. Acta Anaeshesiol Scand. 2002;46(8):980-986

43. Gupta K, Arnold F, Kishor S, Parasuraman S. Concern on prevalence of anemia in pregnant \& lactating women in India. Indian J Med Res. 2007;125(1):99-101.

44. Hassan K, Sullivan KM, Yip R, Woodruff BA. Factors associated with anemia in refugee children. $J$ Nutr. 1997;127(11):2194-2198. https://doi.org/10.1093/jn/127. 11.2194.

45. Korenromp EL, Armstrong-Schellenberg JR, Williams BG, Nahlen BL, Snow RW. Impact of malaria control on childhood anaemia in Africa-a quantitative review. Trop Med Int Health. 2004;9(10):1050-1065.

46. Marchant T, Schellenberg JA, Edgar T, et al. Socially marketed insecticide-treated nets improve malaria and anaemia in pregnancy in southern Tanzania. Trop Med Int Health. 2002;7(2):149-158.

47. Boco AG. Individual and Community Level Effects on Child Mortality: An Analysis of 28 Demographic and Health Surveys in Sub-saharan Africa. 2010; 2010.

48. Platas MR. Africa's Health Tragedy? Ethnic Diversity and Health Outcomes. vols. 17-18. 2010; 2010 Prepared for delivery at the Winter.

49. Haemoglobin Concentrations for the Diagnosis of Anaemia and Assessment of Severity vols. 1-6. Geneva: Switz World Health Organization; 2011.

50. Bhise MD, Patra S. Prevalence and correlates of hypertension in Maharashtra, India: a multilevel analysis. PloS One. 2018;13(2) e0191948.

51. Ngnie-Teta I, Receveur O, Kuate-Defo B. Risk factors for moderate to severe anemia among children in Benin and Mali: insights from a multilevel analysis. Food Nutr Bull 2007;28(1):76-89.

52. Nguyen PH, Nguyen KC, Le MB, et al. Risk factors for anemia in Vietnam. Southeast Asian J Trop Med Publ Health. 2006;37(6):1213.

53. Soh P, Ferguson EL, McKenzie JE, Homs MYV, Gibson RS. Iron deficiency and risk factors for lower iron stores in 6-24-month-old New Zealanders. Eur J Clin Nutr. 2004;58(1):71-79.

54. Balarajan YS, Fawzi WW, Subramanian SV. Changing patterns of social inequalities in anaemia among women in India: cross-sectional study using nationally representative data. BMJ Open. 2013;3(3) e002233.

55. Ejigu BA, Wencheko E, Berhane K. Spatial pattern and determinants of anaemia in Ethiopia. PloS One. 2018;13(5) e0197171.

56. Magalhaes RJS, Clements AC. Mapping the risk of anaemia in preschool-age children: the contribution of malnutrition, malaria, and helminth infections in West Africa. PLoS Med. 2011;8(6) e1000438.

57. Ngesa O, Mwambi H. Prevalence and risk factors of anaemia among children aged between 6 months and 14 years in Kenya. PloS One. 2014;9(11) e113756.

58. Semedo RM, Santos MM, Baião MR, Luiz RR, da Veiga GV. Prevalence of anaemia 
and associated factors among children below five years of age in Cape Verde, West Africa. J Health Popul Nutr. 2014;32(4):646.

59. Ughasoro MD, Emodi IJ, Okafor HU, Ibe BC. Prevalence and risk factors of anaemia in paediatric patients in South-East Nigeria. South Afr $J$ Child Health. 2015;9(1):14-17.

60. Muniz PT, Castro TG de, Araújo TS de, et al. Child health and nutrition in the Western Brazilian Amazon: population-based surveys in two counties in Acre State. Cad Saúde Pública. 2007;23:1283-1293.

61. Singh RK, Patra S. Extent of anaemia among preschool children in EAG States, India: a challenge to policy makers. Anemia. 20142014.

62. Singh MB, Fotedar R, Lakshminarayana J, Anand PK. Studies on the nutritional status of children aged 0-5 years in a drought-affected desert area of western Rajasthan, India. Publ Health Nutr. 2006;9(8):961-967.

63. Desai MR, Terlouw DJ, Kwena AM, et al. Factors associated with hemoglobin concentrations in pre-school children in Western Kenya: cross-sectional studies. Am J Trop Med Hyg. 2005;72(1):47-59.

64. Fotso J-C, Kuate-Defo B. Socioeconomic inequalities in early childhood malnutrition and morbidity: modification of the household-level effects by the community SES. Health Place. 2005;11(3):205-225.

65. Woldie H, Kebede Y, Tariku A. Factors associated with anemia among children aged
6-23 months attending growth monitoring at Tsitsika Health Center, Wag-Himra Zone, Northeast Ethiopia. J Nutr Metabol. 2015;2015.

66. Osório MM, Lira PI, Batista-Filho M, Ashworth A. Prevalence of anemia in children 659 months old in the state of Pernambuco, Brazil. Rev Panam Salud Públic. 2001;10:101-107.

67. Lover AA, Hartman M, Chia KS, Heymann DL. Demographic and spatial predictors of anemia in women of reproductive age in Timor-Leste: implications for health program prioritization. PloS One. 2014 Mar 14;9(3) e91252.

68. Grantham-McGregor S, Ani C. Iron-deficiency anemia: reexamining the nature and magnitude of the public health problem. J Nutr. 2001;131(2):649S-668S.

69. Oppenheimer SJ. Iron-deficiency anemia: reexamining the nature and magnitude of the public health problem. $J$ Nutr. 2001;131 616S-35S.

70. Asobayire FS, Adou P, Davidsson L, Cook JD, Hurrell RF. Prevalence of iron deficiency with and without concurrent anemia in population groups with high prevalences of malaria and other infections: a study in Cote d'Ivoire. Am J Clin Nutr. 2001;74(6):776-782.

71. Kapur D, Agarwal KN, Agarwal DK. Nutritional anemia and its control. Indian J Pediatr. 2002;69(7):607.

72. Five Year Plans. Planning Commission. Delhi: Government of India; 2011. 